\title{
Career Development and Progression of Early Career Academics in Political Science: A Gendered Perspective
}

\section{INTRODUCTION}

This article discusses the career development and progression of Early Career Academics in the discipline of political science ${ }^{i}$ in the United Kingdom, with a focus on whether and to what extent these experiences are gendered. The main aim of this research is to understand Early Career Academics' experiences of acquiring skills and competences necessary for an academic career, including skills-based training, mentoring, and networking, as well as their more general experiences of navigating university and academic life ${ }^{\mathrm{ii}}$. The article therefore links literature on career building and progression, gender and academia, and gender in political science. To date, no research so far has explored how people build careers in the discipline of political science in the UK.

A growing amount of research has demonstrated that women are marginalized in political science across the globe (Allen and Savigny, 2016; Atchison, 2018). In the UK, while men and women are relatively equally represented at the undergraduate and masters levels, just over one-third of academics working in the discipline are women (Pflaeger-Young et al., 2020). Moreover, women are generally concentrated at the bottom ranks of the profession; at the professorial level, the profession is $85 \%$ men (Allen and Savigny, 2016). Research has shown that in the social sciences and humanities, women often leave the field after the doctorate, compared to STEM subjects where the most common time is after the completion of a postdoc (Cidlinská, 2019). Where, why, and how are women in political science 'getting stuck' in the career pipeline? Or is it something more general about the discipline that is putting them off? Allen and Savigny (2016: 998) argue that "institutional practices and cultures, as well as the words and labels that underpin them, structurally disadvantage women political scientists." Examples include the pervasiveness of 'boys' networks' in the discipline, the barriers women face due to childcare responsibilities, and sexist cultures in academia.

This research contributes to the literatures on academic labour and Higher Education (HE) in the UK, as well as to the discipline of political science itself. Who the discipline is composed of is a political matter; it is directly related to its relevance for society more broadly (BriscoePalmer and Mattocks, 2020). Recent calls to diversify political science in the UK (Emejulu, 2019; Wilson, 2019) reflect crucial questions about power and representation. Moreover, research from the gender and organizations literature has shown a need to continue to highlight structural inequalities in the face of a strong narrative of individualism -- the idea that 'one makes one's own destiny' (Gill et al., 2017; Nash and Moore, 2019). The difference in progression is not a case of "fixing women" (and other marginalized groups), but fixing the system (Cidlinská, 2019).

Existing research confirms that career development and progression are experienced differently by different groups (Bhopal, 2018; Mattocks and Briscoe-Palmer, 2016). Delving into the experiences of those at the start of their career is necessary to determine what happens at this critical stage of skill acquisition and career-building. To understand the experiences of ECAs - individuals in both the doctoral and five years postdoctoral stages - in more depth, we employ a mixed-methods approach consisting of a survey alongside in-depth interviews. ECAs face 
distinct challenges relating to precarity, the competitiveness of the job market, and the need to accrue a number of skills and experiences in a short amount of time. An examination of a job advertisement for a Lectureship in Politics at the time of writing in December 2018 lists 14 essential requirements, ranging from "excellent, high-quality publications in top journals," to "a track-record in grant-funded research", to "experience of, and flair for administration and management." Vitae, a UK non-profit organization devoted to supporting researchers' career development, lists the following requirements to "increase your chance of succeeding in academia":

a good publications record, experience of teaching, administration, supervision experience, knowledge of funding opportunities, and ideally evidence of successful funding applications. Experience of professional networking to raise your profile and, increasingly, entrepreneurship or knowledge transfer experience will also be advantageous (Vitae, 2019).

The expectation to fit this into a three- or four-year programme -- the central goal of which is to complete a doctoral thesis -- is high.

The broader structural context of UK HE is vital to understanding these issues. Others have documented the change from universities as public goods to commodities in much more detail (Barcan, 2016; Collini, 2012). The increased precarity, time stress, metricization, and surveillance in university life have led to "a profession stretched to breaking point" (Gill, 2014: 20) and privilege a certain type of labourer -- one who is often male, white, able-bodied, wealthy, and not a primary caregiver (Bhopal, 2018; Huppatz et al., 2018). The paper first reviews the literature on the topic of gender and career development. It then discusses the research methods and methodological approach before outlining the findings. Finally, the discussion and conclusion section contains a number of concrete suggestions for ways the discipline could begin to tackle some of the disparities we identify herein.

\section{GENDER AND CAREER DEVELOPMENT AND PROGRESSION}

There has been a great deal of research examining the gendered nature of academia; a wealth of evidence indicates bias, discrimination, and sexism across the academy. Space does not allow for a full exploration of this literature; instead, we focus on the literature specifically relating to career development. As Curtin et al. (2016: 719) argue, variables such as gender and race "influence feelings of self-efficacy and career interests, because they provide a reciprocal context for both how the world responds to the individual (creating different educational opportunities, for example), and how the individual interprets feedback and experiences from the world around them."

\section{Skills-based training within institutions}

Beyond formal qualifications, the components of a career path are critical developmental experiences (including training); competencies accrued, strengthened, or required; and important career success factors (Carter et al., 2009). Examples of the competencies include critical thinking and problem solving, written and oral communication, digital technology, professionalism and work ethic, teamwork and collaboration, leadership, and global and intercultural fluency (Berdahl and Malloy, 2018). Career success factors refers to often tacit or implicit understandings that an organization might have about what success looks like in a particular role; for example, departments might have a particular teaching focus in mind when recruiting. These three components are a moving target in the case of an increasingly competitive academic job market.

Skills-based training is activities offered by universities designed to inform ECAs and/or help them build skills, therefore targeting both the critical development experiences and 
competencies components of a career path (Carter et al., 2009). Though many universities offer training on research methods, we focus here on professional development training for academic or non-academic jobs; examples may include how to publish or how to apply for grant funding. This training may be offered at the department, faculty, or institutional level. Traditionally, 'training' in European political science was considered an ad hoc activity between supervisor and supervisee (Mény, 2010). As it stands, there is no standardized program of development for social science research students in the UK, with the exception of the Economic and Social Research Council's funded studentship program (which represents a minority of $\mathrm{PhD}$ researchers). Yet, Sverdlik et al. (2018: 373) suggest that the department plays a "major role" in the development of agency and socialization of $\mathrm{PhD}$ researchers, particularly through the opportunities made available to them. This is especially true for social science subjects where ECAs work alone rather than in lab teams (Cidlinská, 2019). Departments often control, for example, whether teaching, mentorship programs, or career development workshops are available to ECAs (Berdahl and Malloy, 2019).

There is little research on skills-based training in political science, and even less on gender and training. Pleschová and Simon (2009) find that ECA women are more likely to want training on teaching, while Gillies and Alldred (2007) find that women may be more likely to be excluded from teaching opportunities. Barr and Wright (2019) explain that, given the evidence on gendered teaching evaluations, ECA teaching staff in their training program are offered the option of having feedback checked over and any offensive or inappropriate content removed before the ECA sees it. More broadly, in a study on researcher development in the Czech Republic, Cidlinská (2019: 369) suggests that because both the idealized career path and the image of an ideal researcher have "masculine characteristics," women may need more support in helping to build key skills. She argues that this should be institutionalized from very early on in the $\mathrm{PhD}$ program by extending mentoring programs to sponsorship, whereby senior colleagues actively play a role in helping someone gain experience. This "will have a greater potential to compensate for the less frequent informal support which women usually receive from senior researchers in comparison to male colleagues" (Cidlinská, 2019: 383; see also Acker, 2008).

\section{Mentoring and networking}

Interpersonal relationships are important for career-building because they offer opportunities for socialization in a professional community and for individuals to build a professional identity. For PhD researchers, mentors may be supervisors, but they do not have to be. Both anecdotal evidence and existing research suggests that mentors can be crucial in career development for academics of all stages (Bhopal, 2018; Bos and Schneider, 2012). People with mentors tend to have better career outcomes (Lunsford, 2012), and more publications and research productivity than those who do not (Humble et al., 2006). Mentoring programs provide the scaffolding for effective career development and professional integration (Monroe, 2003: 94), though some argue that the discipline lacks a mechanism through which quality mentoring might occur (Bos and Schneider, 2012: 223).

Mentors are not accessible to everyone. A study of networking in Dutch academia revealed its gendered nature -- the men in the study had entered the network after being mentored and encouraged by men, and the women by women (Berger et al., 2015). Moreover, the women reported challenges in navigating the masculinized nature of the meetings in the network. Similarly, Acker (2008) notes that women are less likely to have mentors, and that senior men are more likely to choose men as mentees. McGuire and Reger (2003) suggest a feminist comentoring model, to address the masculinization of traditional models of mentoring. This 
model is based on peer support and aims to address both professional and personal goals. Peer mentoring can have particular benefits to the career progression of underrepresented groups and black, Asian, and minority ethnic (BAME) women (Bennion, 2004). Bos and Schneider (2012: 223) specifically suggest better mentoring in the promotion and publication of 'high quality research' in 'high quality research publications', which would help to address some of the gendered career progression differences.

Vitae (2019) suggests that networking is vital in order to raise one's personal profile. Berdahl and Malloy (2018: 78) put it even more simply: "[y]ou need other people to advance your career." However, like mentoring, opportunities for networking are not created equally. Elg and Jonnergård (2003: 164), examining business administration doctoral students making the transition to academics in Sweden, found that as an underrepresented group, women were less likely to have access to both formal and informal networks at work, with one respondent claiming "I will probably never get into the boys' gang." Meanwhile, BAME academics in the UK are less likely than their white counterparts to have access to 'insider' networks (Bhopal, 2014). Moreover, networking takes up time that can be difficult to balance between research, teaching, and personal life, including caring responsibilities (Almack and Churchill, 2007). Cohen et al. (2019) find that academics who are not willing to be physically present for conferences and other similar events may be in danger of becoming marginalized. Many of their respondents viewed mobility - particularly for career progression - as essential (see also Ştefuriuc, 2009).

\section{Discrimination}

Discrimination can be direct - "treating someone with a protected characteristic less favourably than others"; indirect; harassment; or victimization (Equality Act 2010). Discrimination based on protected characteristics such as sex is illegal in the UK. However, evidence demonstrates that indirect, subtle discrimination is more prevalent in academia (Britton, 2017) -- though note that Rollock (2019), in her research on black women professors in the UK, describes ongoing legal cases around racism and harassment. As Leonard (2001) and others argue, it is often the persistence of small seemingly trivial annoyances -- being mistaken for an administrator, for example -- that have a cumulative effect. Similarly, one of the respondents in Allen and Savigny (2016: 1007) indicated that discrimination "is often subtle in academia. [...] It often features neglect and exclusion (from information and consultation for instance) rather than aggression and rejection." An ever-growing volume of work shows bias against women on issues such as teaching evaluations, while an additional literature also shows that women from BAME backgrounds can face oppression and discrimination in the classroom (see for example Britton, 2017; MacNell et al., 2015).

\section{Isolation and exclusion}

Beyond specific elements of gaining skills and competences, research has shown that the academy's formal and informal norms, rules, and values are often highly masculinized (Nash and Moore, 2019), for example, valuing competition rather than collaboration. In other words, organizations are gendered (Acker, 1990). This kind of exclusion is about "not being seen, heard, supported, encouraged, taken into account, validated, invited, included, welcomed, greeted or simply asked along" (Al-Gazali et al., 2013: 38). Atchison (2018: 283)'s analysis demonstrates that men often enter the academy with "pre-established patriarchal support systems" that even senior women can be cut off from.

Challenges are even more profound for BAME women, who experience intersecting forms of oppression and othering (Bhopal, 2018). Research has shown that $\mathrm{PhD}$ researchers who were 
disabled and/or from a BAME background were less likely to want to pursue an academic career (Mattocks and Briscoe-Palmer, 2016). Rollock (2019)'s work on black women professors demonstrates the devastating effects of bullying, racial stereotyping, and racial microaggressions. Meanwhile, other groups such as international academics can face challenges such as language and communication barriers, inequality in career progression and opportunities at work, racism, and xenophobia (Equality Challenge Unit, 2013).

\section{METHODOLOGY AND RESEARCH METHODS}

The aim of the research was to find out ECAs' experiences of professional development and in the analysis to determine to what extent, if at all, these experiences are gendered. We employed a mixed-methods study, consisting of a survey and semi-structured interviews, which has resulted in a thematic analysis. This approach allowed for both breadth and depth, and a focus on experiential evidence (Savigny, 2014). The survey featured questions on elements of professional development, career aspirations, and more general experiences of academia. It included several optional open-text comment boxes for respondents to reflect on the issues in more detail.

The survey was sent to the UK's Political Studies Association Early Career Network members, via email, in spring 2018, and promoted on the ECN's Facebook and Twitter pages. The link was also distributed to all political science departments in the UK, via administrators or heads of department, with a request to forward onto ECAs. It was also available as an offline questionnaire for anyone who requested it in this format. 105 ECAs responded to the survey. With this number we cannot make generalizable claims about this population; however, it is a sufficiently large group so that we can identify trends, themes, and patterns in people's experiences. We received a range of responses demonstrating both positive and negative experiences. The survey's last question, removed in the analysis of the data to preserve confidentiality, was an invitation for respondents to leave contact details if they were interested in participating in a short interview on the topics that the survey covered. In the end we carried out eight semi-structured interviews. Interviews allowed for a more in-depth exploration of people's experiences and provided an additional layer of context to the findings in the survey.

The thematic analysis below is organized according to major discussions in the literature. In categorising responses, we undertook a three-step process. We first together read over all of the responses - text boxes and interview transcripts - to form a general picture. Because most of the data from the survey was open-text boxes, it made sense to analyse this qualitative material together. We then together began identifying broad themes, in reference to the literature, and reflected on these. In a final stage, we refined these themes more comprehensively based on associations between survey and interview responses and identified illustrative examples.

\section{FINDINGS}

The response consisted of an almost equal gender split between those that identified as male $(50 \%)$ and female $(49 \%)^{i i i}$. Based on the split of the profession this is an overrepresentation of women (Pflaeger-Young et al., 2020). 41\% of respondents were postdoctoral and 59\% still completing their PhDs. Around $70 \%$ of respondents were working in academia, and of those, $69.7 \%$ were on fixed-term contracts, indicative of the precarious nature of current academic employment. $45.2 \%$ identified as UK-born nationals and $54.8 \%$ non-UK nationals, also an 
overrepresentation of international academics, with $29 \%$ of all UK-based academics identifying as international (Universities UK, 2017). Non-UK respondents came from all continents except Africa and Antartica; 64\% were from Europe, with Germany the mostrepresented country overall, 18\% from North America, $8 \%$ from Asia, 6\% from South America, and $4 \%$ from Australia. In terms of the interviews, five interviewees identified as women and three as men. Six were postdoctoral and two were still completing. Three interviewees had permanent academic jobs. Half of the interviews were carried out in person and half over the phone.

The survey contained responses from both $\mathrm{PhD}$ researchers and those post- $\mathrm{PhD}$, and we distinguish the responses throughout, as these two categories have different relationships with the institution. Moreover, 'women' are not a monolith, so where possible, we highlight differences in experiences, drawing from the survey data. We outline our findings under the following four categories: the job market; professional development skills-based training within institutions; mentoring and networking; and general isolation, exclusion and discrimination.

\section{The job market}

To set the stage, we asked respondents their general views on the job market. $71.8 \%$ of respondents were concerned about a lack of job opportunities, $68 \%$ worried about entering a competitive job market, $62.1 \%$ concerned about financial challenges, and $51.5 \%$ about combining work with family life. The table below shows the main concerns separated by gender.

Table 1.

\begin{tabular}{|l|l|l|}
\hline Concern(s) & Women, by \% & Men, by \% \\
\hline Lack of job opportunities & 74.5 & 73.0 \\
\hline Competitive job market & 68.6 & 67.3 \\
\hline Combining career with family life & 62.7 & 42.3 \\
\hline Combining career with leisure time & 52.9 & 38.4 \\
\hline Financial challenges & 70.5 & 53.8 \\
\hline Discrimination & 23.5 & 11.5 \\
\hline Isolation and/or exclusion & 27.4 & 19.2 \\
\hline Legal status of residing in UK & 41.1 & 28.8 \\
\hline
\end{tabular}

While these findings cannot be taken as representative of the entire political science ECA body, they do reveal some interesting results. Women report greater concern in all categories. In some, such as lack of job opportunities and a competitive job market, the differences are very minor. In all of the others, there are more significant differences. Based on the literature, it is not surprising that women are more worried about combining a career with family or leisure time, or discrimination. Others are more surprising: why are women more worried about finances, or about the legal status of residing in the UK, than men? 


\section{Skills-based training within institutions}

Findings indicate that career development provision within doctoral programmes varies considerably throughout the UK. Some institutions offer comprehensive programmes, while others are complacent in encouraging ECAs to complete research development activities. Overall, the impression that emerged was that even though UK PhD study is very self-directed (in comparison to the North American system, for example), this does not mean that career development should be as well.

In general, over half of our respondents $(57.3 \%)$ felt that they were supported by their institution or department in their career development. 50.9\% of women felt supported, and 63\% of men, demonstrating a slight gender difference and confirming the literature cited above. When asked what career development support was offered, respondents shared critiques rather than good practices:

"The university makes me feel like a number in their statistics. They push us through the system as quickly as they can [...] without actually caring what happens to us after we graduate. There are some 'training opportunities', which are in my eyes very superficial and are not tailored to the needs of individual students" (survey respondent, woman, postdoctoral)

"It would help if at least some aspects of professional development were structured and automatic rather than, perhaps, vulnerable to bias or favouritism" (survey respondent, man, early stages PhD)

So what do ECAs want? Firstly, ECAs would like discipline-specific training. Secondly, there was a feeling from multiple participants that training needs to be personal: "I would have needed some serious mentoring, someone talking to me about my concerns, my career options etc - not talks about "how to publish a paper"..." (survey respondent, woman, postdoctoral). Another survey respondent indicated that they wished the university included ECAs in the planning of training and in the running of the department, giving them greater representation in decision-making overall. Multiple respondents mentioned teaching experience and/or opportunities to pursue a teaching qualification such as Associate Fellowship of the Higher Education Academy. Some universities offer this to doctoral researchers, but some do not ${ }^{\mathrm{iv}}$. While over half of respondents were pleased with development opportunities, more could be done in order to standardise practices and take the precarious labour conditions of future academics more seriously.

\section{Mentoring and networking}

As discussed above, mentoring and networking are important steps in building and strengthening reputation and membership in an academic community. Acker and Haque (2010) argue that doctoral researchers are often focused on getting through their programmes, and surviving financially, leaving little time for professional development; this means in the absence of comprehensive professional development programmes, individuals often rely on information from supervisors and/or other mentors.

ECAs highlighted mentoring relationships and/or networking as significant in their career progression. Two thirds (65\%) of respondents reported that they had access to a mentor: $59.6 \%$ of women and $71.6 \%$ of men. We cannot generalise this to be representative of the entire discipline, but there is a clear gendered difference evident among respondents to this survey. One respondent nicely summarized her experience of being mentored, and the advantages that 
had brought her: "Having a mentor is an excellent way to learn more about the field and, especially as a woman, to feel supported and build a network" (woman, late stages PhD). A number of individuals wrote that they had been assigned a mentor, but did not know who that person was.

One finding that emerged is many women would prefer a mentor who is also a woman, confirming findings from existing research (Cidlinská, 2019):

"As a woman in politics I would greatly benefit from having a mentor - I lack any career guidance from colleagues or line manager and my department is heavily male" (survey respondent, woman, postdoctoral).

Gender disparities were evident in the descriptions of experiences of mentorship, such as this comment: "Has been hugely helpful to have senior academics mentoring me, and championing me in the job/PhD application market" (survey respondent, man, early stages PhD). The respondent's use of the word 'championing' demonstrates the benefit of not having someone to simply mentor you, but someone that actively promotes or sponsors you (SLAC, n.d.).

One relationship that is crucial for career- and confidence-building is that of the supervisorsupervisee (Hemmings, 2012). Sverdlik et al. (2018) report that many $\mathrm{PhD}$ researchers believe the ideal role of supervisor is that of a mentor. However, the main role of the supervisor is to guide the PhD researcher through to completion, not to provide mentorship (Humble et al., 2006). Some participants classified their PhD supervisors as a mentor during their doctoral study, while some did not. In some of the former cases, the mentorship also continued once the $\mathrm{PhD}$ was completed. Several responses demonstrated gendered effects, such as this one:

"I felt isolated since my male supervisors were both writing papers with their male supervisees" (survey respondent, woman, postdoctoral)

As an ECA, is one assigned a mentor, or does one choose one? One survey respondent explained that "mentorships work better when it is organic" (woman, postdoctoral). Some participants emphasized that it was not important to have a mentor from the same institution, that alternatively it was "crucial to have someone outside your institution on your side" (man, early stages PhD). Several women respondents shared how the mentors they had built relationships with were people outside of academia, such as former managers and informal contacts.

With regards to networking, 52 respondents (49.5\%) indicated that they participate in networking events such as conferences or workshops. Breaking this down further, this is $50.9 \%$ of women and $50 \%$ of men. Most of these respondents demonstrated a positive approach to networking but suggested a need for better direction on how to network.

"Within the department there are opportunities to network, however getting to know about these was difficult at first (I seemed to have been left out of the crucial mailing lists for the first good year and a half!). PhD networking opportunities are much better advertised, so I have made some good connections that have led to important pieces of work. [...] but there is still room for improvement, in bringing ECRs together." (survey respondent, women, postdoctoral)

"Some help on how best to network would be most useful" (survey, women, postdoctoral)

“... [conferences] had a lot of benefits [...]. They were important people from your field and politicians you could just network with. [This] becomes really handy because academics and people from 
universities came. That is how I got one of my teaching jobs because they said they need someone last minute can you, if you would be interested" (interviewee, man, postdoctoral)

The third quote demonstrates just how important networking can be -- this individual received a job via connections made through networking. Such experiences were not shared by women respondents.

From the 54 respondents that did not participate in networking events, again there was an equal split between women and men (1 respondent preferred not to say). However, gender disparities became evident when recognising underlying factors for individual reluctance to participate in networking. Our survey identified confidence as a gendered factor in the responses. $74 \%$ of women and $46.1 \%$ of men reported that a lack of confidence (academic and/or personal) was a reason that they did not participate in networking events.

"Networking is a very white-male space that I've never felt comfortable with" (survey respondent, woman, mid-stages PhD).

"Networking events tend to favour the 'bold and brash' (usually male) individuals who seemingly have no fear. I'm hugely intimated by this style. I have attended roundtable speed dating style of networking I mentoring which I find more helpful" (survey respondent, woman, postdoctoral).

"Conference attendance only form of networking, is expensive, and lack of women in the field can lead to isolation at events in spite of efforts to mingle (particularly in the UK) " (survey respondent, woman, postdoctoral).

In comparison, a male respondent expressed how confident he felt by choosing to not engage in networking or needing to do so in order to develop his career:

"I don't like to network for the sake of it. I'm quite relaxed about doing my job well, being friendly and engaging when I meet people, and putting together the best applications/submissions to a journal whenever I go on to do it, rather than relying on my networking abilities" (survey respondent, male, postdoctoral)

Overall, we find some gendered differences with regards to experiences of mentoring and networking. Men were more likely to have a mentor and to report positive experiences of networking and mentoring relationships. Though men and women participated in networking at roughly the same rate, men reported greater confidence.

\section{Discrimination}

To understand potential inequalities in career-building and progression in more detail, the survey asked whether respondents had experienced discrimination. This was separated into three categories -- from colleagues/peers, students, and/or departments and institutions. In total, $22 / 105$ people reported they had faced some type of discrimination, around $21 \%$ of respondents. We can compare it to Allen and Savigny's (2016) survey, which revealed that $58 \%$ of women respondents and $17 \%$ of men experienced sexual discrimination in their career (note that we did not specify discrimination on the basis of sex in the survey, but rather left it open).

Nearly one-fifth of women (19.6\%) and 3.8\% of men reported discrimination from students. Interestingly, both men were from outside of the UK, meaning no British men reported discrimination from their students. Respondents' comments include: 
"I regularly received discriminatory behaviours from students. This included behavioural issues in lower years and discourtesies such as speaking over me when I lectured, sniggering, laughing, sleeping when I was lecturing, playing on phones, questioning my marking" (survey respondent, woman, postdoctoral)

"I am the only female lecturer in my department and the students treat me differently. My colleagues are all male and 10+ years older than me. Students accept them as authority figures but regularly challenge me in ways they do not do to my male colleagues" (survey respondent, woman, postdoctoral)

There were also specific comments relating to discrimination based on race and/or ethnicity, and geographical origin:

"Students say they would prefer UK lecturer" (survey respondent, woman, postdoctoral)

"Being a non-white young female means there will be everyday low-level prejudices / discrimination. [...] inappropriate comments and unconscious bias" (survey respondent, woman, postdoctoral)

In total, $15.6 \%$ of women and $3.8 \%$ of men reported discrimination from colleagues and peers:

"Mild sexism and misogyny, dept as colleagues treat me as if I was a permanent member of staff in terms of my responsibilities, but lack benefits and security of permanence eg mentoring and career development opportunities" (survey respondent, woman, postdoctoral)

“...male PhD students have been taken under the wing of academics more - given informal research assistance work, administration roles that has not been advertised etc" (survey respondent, woman, postdoctoral)

We also asked about discrimination on a wider scale, from departments and institutions. Here, we were interested in institutional cultures: was there evidence of a persistent 'chilly climate' (Sandler and Hall, 1986) for women? $15.6 \%$ of women and $7.7 \%$ of men indicated that they had experienced this type of discrimination.

"I am mostly worried about the impact of institutional sexism holding back my progression, which is something that seems to be going on around me" (survey respondent, women, postdoctoral).

Specific race-based discrimination against BAME respondents was also evident:

"Very casual and implicit racism, e.g. colleagues constantly highlighting I am coming from a different country in a range of situations where this shouldn't be a point of discussion" (survey respondent, man, postdoctoral)

These findings therefore concur with existing research that women experience subtle and overt discrimination more often than men (Allen and Savigny, 2016; Leonard, 2001). This was most evident with regards to discrimination from students.

\section{Isolation and exclusion}

Achieving goals in the early stages of an academic career is dependent on building confidence, recognition, productivity, and sophistication in a professional capacity (Akerlind, 2010). It is also about achieving a sense of belonging in a professional community. In this final section we discuss respondents' experiences of isolation and exclusion. As argued above, career 
development and progression may be hindered by these "[d]aunting inequities and painful struggles" (Harris and Gonzalez, 2012: 2). It is therefore pertinent to try to understand in more depth the potential impacts that arise from being isolated and excluded within a department, institution, or academic community. We did not define these terms in the survey, but rather left it open for respondents to interpret as they saw fit.

Overall, $48 \%$ of women and $38 \%$ of men indicated that they had experienced isolation, while $29.4 \%$ of women and $19.2 \%$ of men indicated that they had experienced exclusion, indicating slight gender differences. Many open-text responses relating to this question mentioned that the experience of completing a $\mathrm{PhD}$, as well as the nature of academic work in general, was isolating by default; this is not a surprising finding. There was also isolation in teaching reported. For example, two respondents, both women, reported being excluded from teaching in their department, even when they followed the correct procedure to apply. Another respondent, also a woman, reported that male colleagues had told her that the only reason she got a teaching position was because of Athena SWAN ${ }^{\mathrm{v}}$. Others expanded on different aspects of isolation:

"I've felt isolated [...] being the only black person in the department. [...] Last week I attended an event and [...] I was the only black person in the room, again. [...] It's difficult" (interviewee, woman, late stages $\mathrm{PhD}$ )

"The various precarious teaching jobs I've held are extremely isolating, particularly when real life gets in the way. When my dad died and I flew back to [country] for his funeral that meant that I had to give up my teaching job to do it. Absolutely inhuman" (survey respondent, man, postdoctoral)

We see two very different examples of isolation here, both to do with structural issues in academia. We also read reports of individuals - mainly men - feeling excluded because of their political views and/or class, neither of which were raised by women. For example, a late stages $\mathrm{PhD}$ researcher (man) commented that when he was a student he was "ganged up on ... for not having the right views."

Overall, women reported more cases of isolation and exclusion, in line with the literature. In free text boxes and interviews, white women tended to raise age/youth as the biggest source of discrimination and isolation, whereas for BAME women, it was race. ECAs that came from countries outside of the UK - particularly women - can also face additional challenges, particularly from students but also from peers.

\section{DISCUSSION AND CONCLUSIONS}

Overall, results from this research demonstrate that some elements of professional development for Early Career Academics are gendered. Evidence shows that certain worries about academic careers, as well as experiences of mentoring, networking, and teaching (specifically discrimination from students), are gendered. The limitations of our findings mean that these results pertain to the sample only; however, many of them mirror previous research on the profession in the UK (Allen and Savigny, 2016). Though we are unable to offer a full intersectional analysis in this paper, we also have highlighted where BAME scholars and international ECAs may face additional challenges.

These findings are not an explanation in of themselves for the underrepresentation of women in the profession. Rather, they contextualize some of the challenges that women face early in 
their careers. On their own, each experience might seem trivial. Taken together, they are indicative of a system in which some people have more access and more advantage than others (Berger et al., 2015), which is compounded by the precarious, insecure, surveilled nature of academic employment (Gill, 2014). Many survey respondents and interviewees raised concerns that paint a picture of a broken system. Academia has been described by Gill (2010) as a kitchen, 'too hot for almost everyone'. The academy is a filtering system "in which those who are privileged in terms of gender, race, health, and social class are vastly over-represented" (Jones and Oakley, 2018) -- those who can cope with the heat of the kitchen.

Who is responsible for career development and progression? It is a question that needs serious consideration. Berdahl and Malloy (2018)'s approach is a practical how-to one; they stress the importance of individual agency. We agree with this to a point -- there is no doubt that individuals are responsible for cultivating and honing many of the skills and competencies that are required to obtain an academic job. However, this perspective minimizes structural barriers and the wider cultures of sexism, racism, and other types of discrimination. These issues are rarely at the forefront of official discussions in the academy and so remain silenced (Gill, 2014). Major change is not possible until the sector as a whole grapples with these challenges; a multilevel, multi-pronged approach is necessary. The UK Political Studies Association, for example, has made a number of positive changes over the last several years (see Awesti et al., 2016; Wilson, 2019), such as the introduction of a ban on all-male panels at events, childcare provision at the annual conference, and a new PhD scholarship, among others. But more work by other actors -- including supervisors, departments, institutions, and the broader HE regulatory and policy environment -- is urgently needed.

With regards to skills-based training, much more attention should be paid to the provision of training at $\mathrm{PhD}$ and postdoctoral stages (Mény, 2010). This is imperative given the everchanging harsh structural conditions of the labour market. Ultimately training programs should be helping to create the next generation of political scientists (Laver, 2005); universities and individual departments should take increased responsibility in helping $\mathrm{PhD}$ researchers prepare for the job market. Standardized programs are preferable over the apprenticeship model, where ECAs are at the mercy of their supervisors and great variation between individual experiences is likely (Laver, 2005; Thorlakson, 2005). Programs that leave students to their own devices are no longer suitable given the conditions of the job market.

Regarding mentorship and networking, we issue a strong call for departments to acknowledge the benefits and value of mentoring -- particularly for women, given the gendered career development discrepancies within the discipline. Opportunities for mentoring and networking should be visible and transparent. We recommend mentoring be rolled out as a standard procedure for ECAs, in order to avoid possible concerns of favouritism. Adopting a curricula embedded career preparation programme (Collins et al., 2012) would take responsibility away from individual supervisors and reduce feelings of missed opportunities. A further suggestion is women-only mentoring events (Bos and Schneider, 2012).

Even though we are both at the start of our academic careers, we cannot help but notice the longevity of some of these conversations on gender in the profession, and how while the amount of research on the topic has increased, this has not been accompanied by many improvements in the 'real world.' These measures we have discussed will not solve any major structural barriers, but they are a start to help to tackle the gendered experiences described in this paper. It is time for universities and the sector more broadly to take these findings into account and begin to build an academy that is more diverse and inclusive. They need to be 
noticed on a broader level -- beyond people in political science (men and women, staff and students) who care.

\section{Bibliography}

Acker J (1990) Hierarchies, jobs, bodies: a theory of gendered organizations. Gender and Society 4(2): 139-158.

Acker J (2008) Helpful Men and Feminist Support: More than Double Strangeness. Gender, Work and Organization 15(3): 288-293.

Acker S and Haque E (2010) Doctoral students and a future in academe? In: McAlpine L and Akerlind GS (eds) Becoming an Academic: International Perspectives. Houndsmills, UK: Palgrave Macmillan, pp. 96-124.

Akerlind GS (2010) Developing as a researcher post-PhD. In: McAlpine L and Akerlind GS (eds) Becoming an Academic: International Perspectives. Houndsmills, UK: Palgrave Macmillan, Pp.45-70.

Al-Gazali L, Valian V, Barres B, Andrei EY, Wu LA, Handelsman J and Husu L (2013) Laboratory life: scientists of the world speak up for equality. Nature 495(7439): 35-38.

Allen N and Savigny H (2016) Experiencing gender in political science: results from a practitioner survey. British Journal of Politics and International Relations 18(4): 997-1015.

Almack K and Churchill H (2007) Power and the PhD Journey: 'Getting in' and 'Getting on'. In: Gillies V and Lucey H (eds) Power, Knowledge and the Academy. London: Palgrave Macmillan.

Atchison AL (2018) Towards the good profession: improving the status of women in political science. European Journal of Politics and Gender 1(1-2): 279-298.

Awesti A, Flinders M, and Savigny H (2016) Pursuing the Diversity and Inclusion agenda: The PSA in the UK. European Political Science 15(4): 508-518.

Barcan R (2016) Academic life and labour in the new university: Hope and other choices. London. Routledge.

Barr $\mathrm{M}$ and Wright $\mathrm{P}$ (2019) Training graduate teaching assistants: what can the discipline offer? European Political Science 18(1): 143-156.

Bennion EA (2004) The Importance of Peer Mentoring for Facilitating Professional and Personal Development. Political Science and Politics, 37(1): 111-113.

Berdahl L and Malloy J (2018) Work Your Career: Get What You Want from Your Social Sciences or Humanities PhD. Toronto: University of Toronto Press. 
Berdahl L and Malloy J (2019) Departmental Engagement in Doctoral Professional Development: Lessons from Political Science. Canadian Journal of Higher Education 49(2): 37-53.

Berger L, Benschop Y and van den Brink M (2015) Practising Gender When Networking: The Case of University-Industry Innovation Projects. Gender, Work and Organization 22(6): 556-578.

Bhopal K (2018) White Privilege: The Myth of a Post-Racial Society. Bristol: Policy Press.

Bhopal K (2014) The Experience of BME Academics in Higher Education: Aspirations in the Face of Inequality, London: Leadership Foundation for Higher Education.

Bos AL and Schneider MC (2012) Mentoring to Fix the Leaky Pipeline. Political Science and Politics 45(2): 223-231.

Briscoe-Palmer S and Mattocks K (2020) Race, Intersectionality and Diversity in European Political Science. In Boncourt T, Engeli I and Garzia D (eds) Political Science in Europe: Achievements, Challenges, Prospects. London: ECPR Press/Rowman \& Littlefield International. Pp. 199-219.

Britton D (2017) Beyond the chilly climate: the salience of gender in women's academic careers. Gender \& Society 31(1): 5-27.

Carter GW, Cook KW, Dorsey DW (2009) Career Paths: Charting Courses to Success for Organization and Their Employees. Chichester, UK: Wiley-Blackwell.

Cidlinská K (2019) How not to scare off women: different needs of female early-stage researchers in STEM and SSH fields and the implications for support measures. Higher Education 78(2): 365-388.

Cohen S, Hanna P, Higham J, Hopkins D, Orchiston C (2019) Gender discourses in academic mobility. Gender, Work and Organization 27(2): 149-165.

Collini S (2012) What are universities for? London: Penguin.

Collins TA, Knotts HG and Schiff J (2012) Career Preparation and the Political Science Major: Evidence from Departments. Political Science and Politics, 45(1) 87-92.

Curtin N, Malley J and Stewart AJ (2016) Mentoring the Next Generation of Faculty: Supporting Academic Career Aspirations Among Doctoral Students. Research in Higher Education 57(6): 714-738.

Elg U and Jonnergård K (2003) The Inclusion of Female PhD Students in Academia: A Case Study of a Swedish University Department. Gender, Work \& Organization 10(2): 154-174.

Equality Act (2010) United Kingdom. Available at:

http://www.legislation.gov.uk/ukpga/2010/15/contents (Accessed: 20 February 2019). 
Equality Challenge Unit (2013) Improving the experiences of international staff in UK HE. Available at: https://www.ecu.ac.uk/publications/improving-experiences-internationalstaff/ (Accessed: 23 February 2019).

Gill R (2010) Breaking the silence: The hidden injuries of neo-liberal academia. In: Flood R and Gill R (eds) Secrecy and Silence in the Research Process: Feminist Reflections. London: Routledge, pp.228-244.

Gill R (2014) Academics, cultural works and critical labour studies. Journal of Cultural Economy 7(1): 12-30.

Gill R, Kelan EK and Scharff CM (2017) A Postfeminist Sensibility at Work. Gender, Work and Organization 24(3): 226-244.

Gillies V and Alldred P (2007) Making the right connections: 'knowledge' and power in academic networking. In Gillies V and Lucey $\mathrm{H}$ Power, Knowledge and the Academy: The Institutional is Political. Houndmills, UK: Palgrave Macmillan. Pp.105-121.

Harris, AP and Gonzalez CG (2012) Introduction. In: Gutiérrez y Muhs G, Flores Niemann Y, Gonzalez CG and Harris AP (eds) Presumed Incompetent: The Intersections of Race and Class for Women in Academia. Logan, Utah: Utah State University Press, pp. 1-14.

Hemmings B (2012) Sources of research confidence for early career academics: a qualitative study. Higher Education Research and Development 31(2): 171-184.

Humble ÁM, Solomon CR, Allen KR, Blaisure KR and Johnson MP (2006) Feminism and Mentoring of Graduate Students. Family Relations 55(1): 2-15.

Huppatz K, Sang K, Napier J (2018) 'If you put pressure on yourself to produce then that's your responsibility': Mothers' experiences of maternity leave and flexible work in the neoliberal university. Gender, Work, \& Organization 26(6): 772-788.

Jones SA and Oakley C (2018) The Precarious Postdoc: Interdisciplinary Research and Casualised Labour in the Humanities and Social Sciences. Available at: http://www.workingknowledgeps.com/wpcontent/uploads/2018/04/WKPS_PrecariousPostdoc_PDF_Interactive.pdf (Accessed: 20 February 2019).

Laver M (2005) The objectives and design of European doctoral programmes in political science. European Political Science 4(1): 95-101.

Leonard D (2001) A Woman's Guide to Doctoral Studies. Buckingham, UK: Open University Press.

Lunsford L (2012) Doctoral Advising or Mentoring? Effects on Student Outcomes.

Mentoring \& Tutoring: Partnership in Learning, 20 (2): 251-270.

MacNell L, Driscoll A, and Hunt AN (2015) What's in a Name: Exposing Gender Bias in Student Ratings of Teaching. Innovative Higher Education 40(4): 291-303. 
Mattocks K and Briscoe-Palmer S (2016) Challenges facing minority politics PhD students in the United Kingdom: Women, people of Black and Ethnic minority origin, and Disabled persons. European Political Science 15(4): 476-492.

McGuire GM and Reger J (2003) Feminist Co-Mentoring: A Model for Academic

Professional Development. National Women's Studies Association Journal, 15(1): 54-72.

Mény Y (2010) Political science as a profession. European Political Science 10(1S): S11-S21.

Monroe KR (2003) Mentoring in Political Science. Political Science and Politics 36(1): 93-96.

Nash M and Moore R (2019) 'I was completely oblivious to gender': an exploration of how women in STEMM navigate leadership in a neoliberal, post-feminist context. Journal of Gender Studies 28(4): 449-461.

Pflaeger Young Z, Amery F, Holden Bates S, McKay S, Miller C, Billings T, Hayton R, Holt M, Khatri J, Marvin M, Ogunsanya L, Ramdehal A and Sullivan R (2020) Women in the Profession: An Update on the Gendered Composition of the Discipline and Political Science Departments in the UK. Political Studies Review.

Pleschová G and Simon E (2009) Teacher Training for Political Science PhD Students in Europe: Determinants of a Tool for Enhanced Teaching in Higher Education. Journal of Political Science Education 5(3): 233-249.

Rollock N (2019) Staying Power: The career experiences and strategies of UK Black female professors. University and College Union.

Sandler BR and Hall RM (1986) The Campus Climate Revisited: Chilly for Women Faculty, Administrators, and Graduate Students, Washington: Association of American Colleges and Universities.

Savigny H (2014) Women, Know Your Limits: Cultural Sexism in Academia. Gender and Education 26(7): 794-809.

SLAC (n.d.) The key role of sponsorship. Available at:

https://inclusion.slac.stanford.edu/sites/inclusion.slac.stanford.edu/files/The_Key_Role_of_a Sponsorship_for_Diverse_Talent.pdf (accessed 14 February 2020).

Ştefuriuc I (2009) Introduction: Building an Academic Profile - Considerations for Graduate Students Embarking on an Academic Career in Political Science in Europe. European Political Science 8(2): 138-142.

Sverdlik A, Hall NC, McAlpine L and Hubbard K (2018) Journeys of a PhD student and unaccompanied minors. International Journal of Doctoral Studies 13: 361-388.

Thorlakson L (2005) Models of doctoral training in European political science. European Political Science 4(1): 82-94.

Universities UK (2017) International facts and figures. Available at:

https://www.universitiesuk.ac.uk/policy-and- 
analysis/reports/Documents/International/International_Facts_and_Figures_2017.pdf (Accessed: 12 February 2019).

University and College Union (2016) Precarious work in Higher Education: A snapshot of insecure contracts and institutional attitudes. Available at: https://www.ucu.org.u Pitt k/media/7995/Precarious-work-in-higher-education-a-snapshot-of-insecure-contracts-andinstitutional-attitudes-Apr-16/pdf/ucu_precariouscontract_hereport_apr16.pdf (Accessed: 2 February 2019).

Vitae (2019) Pursuing an academic career. Available at: https://www.vitae.ac.uk/researchercareers/pursuing-an-academic-career (Accessed 15 January 2020).

\footnotetext{
'We use the term "political science" for consistency, but please note that the discipline is also known as "politics" and "political studies" in the UK.

ii Though we recognise that there are many barriers to starting a PhD, we do not capture these in this research. We also do not cover non-academic career development extensively. We would welcome and encourage future research on both topics.

iii $1 \%$ of respondents did not answer this question and one person ticked preferred not to say. Future research should consider accounting for different gender identities.

iv Not all universities offer teaching or teaching-associated roles to their doctoral researchers. However opportunities may be available at other universities.

${ }^{v}$ Advance HE's Athena SWAN Charter encourages and recognizes work undertaken to advance the careers of women across HE.
} 